\title{
Prevalence of cancer incidences in Bihar, India due to poisoning in groundwater
}

\author{
A. Kumar, R. Kumar, M. Ali \& A.K. Ghosh \\ Mahavir Cancer Institute and Research Centre, Patna, Bihar, India
}

\begin{abstract}
Arsenic (As) poisoning in groundwater in Bihar (India) has caused various health related issues in the village population. In State of Bihar, India, it is estimated that more than 5 million people are drinking water with As concentrations greater than $10 \mu \mathrm{g} \mathrm{L}^{-1}$ (WHO permissible limit), and presently, the groundwater As contamination has been confirmed in 18 districts of the state of Bihar as per our study. The As contamination in the groundwater was maximum observed in Buxar district in the Simri village with maximum level of $1929 \mu \mathrm{g} \mathrm{L}^{-1}$. Apart from the symptoms of arsenicosis, the other symptoms observed were general body weakness, loss of appetite, anemia, cough or bronchitis, constipation, change in the mood or behavior, mental stress, hormonal imbalance etc. Our study has confirmed very high As contamination in the groundwater as well as in their biological samples of As exposed population. The present study deals with the evaluation of As contamination in groundwater and its correlation with incidences of cancer cases in As hit areas of Bihar. This will enable to make a strategic policy to control the cancer incidences in these areas with As contaminated aquifers.
\end{abstract}

\section{INTRODUCTION}

In the Gangetic flood plain region of Bihar, the arsenic (As) poisoning in groundwater has led to various health related problems in the population. The population exhibited typical symptoms of arsenicosis like hyperkeratosis in sole and palm, melanosis, pigmentations in skin, general body weakness, loss of appetite, anemia, cough or bronchitis, constipation, change in the mood or behavior, mental stress, hormonal imbalance etc. The incidences of cancer cases have increased many folds in these As hotspot areas in recent times. Approximately, 80,000 new cancer cases are reported yearly from this state and our institute - Mahavir Cancer Sansthan \& Research Centre, Patna, Bihar alone registered approximately 26,000 new cancer patients in 2016-17. The cancer cases reported are squamous cell carcinoma of skin, liver and gall bladder cancer, renal cell carcinoma, breast cancer, melanoma, leukemia, lymphoma etc. The present study evaluates the correlation between As contaminations in groundwater and cancer incidences.

\section{METHODS/EXPERIMENTAL}

\subsection{Ethical approval}

The research work was approved by the IEC (Institutional Ethics Committee) of the institute as the work was on human subjects. The survey work was carried out from February of 2016 till date when the cancer patients from the village reported in our cancer research center.

\subsection{Location}

The study was done in the As hit villages of Buxar, Saran, Patna and Samastipur villages of state Bihar, India.

\subsection{Sample collection \& survey}

Cancer patients were selected from the As hit village for the study to know their blood As levels as well as hair As levels.

Apart from this, random 400 cancer patient's blood samples were collected from the pathology department of the institute and were assayed to know their blood As levels.

The water samples were collected from the cancer patient's households. After collection, all the samples were digested using concentrated $\mathrm{HNO}_{3}$ on hot plate under fume hood and total As concentration (inorganic form) was estimated as per the protocol of (NIOSH, 1994) through graphite furnace atomic absorption spectrophotometer (Pinnacle 900T, Perkin Elmer, Singapore). Simultaneously, health assessment of the population was also done through a health survey questionnaire proforma. For determining the exact location of the hand pump, hand held Global Positioning System (GPS) receivers (Garmin etrex 10, of USA) with an estimated accuracy of $\approx 10 \mathrm{~m}$ were utilized. 


\section{RESULTS AND DISCUSSION}

\subsection{Arsenic assessment in cancer patient's blood samples}

The study shows novel findings ever explored in this area. The maximum As concentration in blood samples of cancer patients observed was $461.2 \mu \mathrm{g} \mathrm{L}^{-1}$ (Fig. 1).

\subsection{Health assessment}

The rural population exhibited the typical symptoms of arsenicosis like hyperkeratosis in palm and sole, melanosis in palm and sole, blackening of tongue, skin irritation, anemia, gastritis, constipation, loss of appetite, bronchitis \& cough, etc. The cancer incidences were very severely found along with high As concentration in their water samples. The cancer cases recorded were squamous cell carcinoma of skin, renal cell carcinoma, ovarian cancer, breast cancer, skin melanoma etc. in the village population (Fig. 2).

The maximum As concentration in the hair samples were observed in $6.3 \mathrm{mg} \mathrm{kg}^{-1}$ (Fig. 2B) while in hand pump water was $826.2 \mu \mathrm{g} \mathrm{L}^{-1}$ As determination

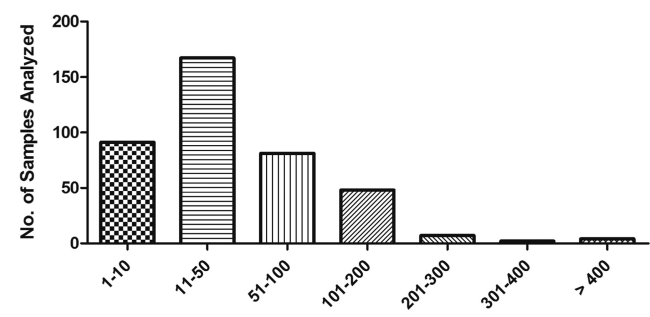

Figure 1. Arsenic concentration in blood samples of cancer patients analyses through GF-AAS (ANOVA-Dunnett's Test, $\mathrm{P}<0.05)$.

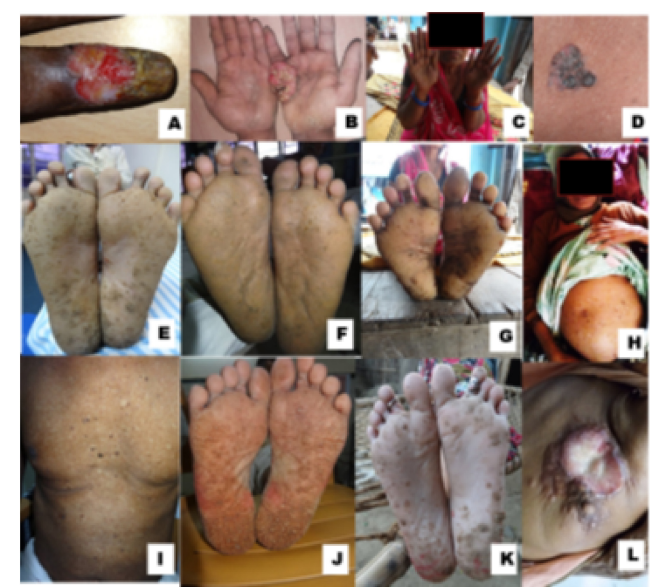

Figure 2. Showing cancer cases in the population along with the arsenicosis symptoms (A, B, E \& F - Squamous cell carcinoma, C, G \& L - Breast cancer, D - Skin melanoma. I \& J - Renal cell carcinoma, H \& K - Ovarian cancer). in urine, hair and nail are considered as most reliable indicator of exposure. Hair samples are used as a biomarker for As exposure because inorganic As and dimethylarsinic acid are stored in hair root and thus reflect past exposure (Yoshida et al., 2004). Elevated As levels in hair indicates the past exposure of 6-12 months (NRC, 2001).

Various molecular pathways have been deciphered which indicates that As is one of the toxic agent which is causing cancer in the population under study. Arsenic also has the affinity to directly bind sulfhydryl (SH) moieties and conversion of SH to S-S by free radicals (ROS) leading to cause severe toxicity at the cellular level. Although, interaction between As and thiol groups may occur in 200 known human proteins (Abernathy et al., 1999).

The other health related assessments showed hormonal imbalance in the population. The rural population exhibited elevated levels of serum estrogen while decreased levels of serum testosterone levels denotes that the As contamination in groundwater and its consumption by the rural population has caused severe health problems to them (Kumar et al., 2015, 2016). The entire study reveals that high As concentration in groundwater has somehow led to cause cancer incidences in the As hit area. Map of the occurrence of As contamination in groundwater and the corresponding incidences of cancer in Bihar is presented in Figure 3.
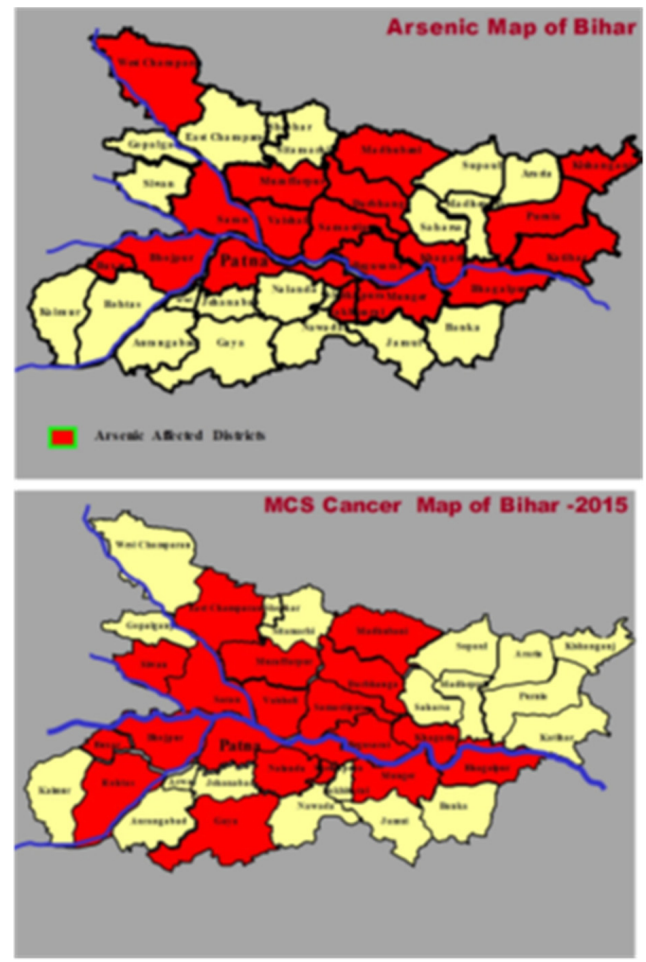

Figure 3. Comparison between arsenic map of Bihar, India and cancer map of Bihar. 


\section{CONCLUSIONS}

The study thus concludes that high As contamination in the groundwater has led to cause incidences of cancer in these hotspot areas. Many As induced health related problems were also observed in the population like keratosis, melanosis, leuco-melanosis, hormonal imbalance. The As map of the state with the cancer map are almost similar correlates the present study.

\section{ACKNOWLEDGEMENTS}

The authors acknowledge support extended by Mahavir Cancer Sansthan and Research Centre, Patna for providing laboratory and other infrastructural facilities for this study.

\section{REFERENCES}

Abernathy, C.O., Liu, Y.P., Longfellow, D., Aposhian, H.V., Beck, B., Fowler, B., Goyer, R., Menzer, R., Rossman, T., Thompson, C. \& Waalkes, M. 1999. Arsenic: health effects, mechanisms of actions, and research issues. Environ. Health Perspect. 107(7): 593-597.
Kumar, A., Ali, M., Rahman, S.M., Iqubal, A.M., Anand, G., Niraj, P., Shankar, P. \& Kumar, R. 2015. Ground water arsenic poisoning in "Tilak Rai Ka Hatta" village of Buxar district, Bihar, India causing severe health hazards and hormonal imbalance. J. Environ. Anal. Toxicol. 5(4): 290. 1.

Kumar, A., Rahman, M.S., Iqubal, M.A., Ali, M., Niraj, P.K., Anand, G. \& Kumar, P. 2016. Ground water arsenic contamination: a local survey in India. Int. J. Prev. Med. 7: 100.

NRC. 2001. Arsenic in drinking water: 2001 update. The National Academies Press, Washington, DC.

Yoshida, T., Yamauchi, H. \& Fan, S.G. 2004. Chronic health effects in people exposed to arsenic via the drinking water: dose-response relationships in review. Toxicol. Appl. Pharmacol. 198(3): 243-252. 